\title{
A Success Story of Organizing Small Scale Farmers in Kenya: It's Possible Replication for the Payment of Environmental services?
}

\author{
Mogens Buch-Hansen*
}

International Development Studies, Department of Society and Globalisation, Roskilde University, P.O. Box 260, DK4000 Roskilde, Denmark

\begin{abstract}
The hypothesis of this article is that managing agricultural landscapes for reducing greenhouse gas emissions as a Payment for Environmental Services mechanism [PES] will be of major significance after the 2012 Kyoto Protocol era. The large number of small scale farmers in developing countries, and not least in Africa South of Sahara [SSA], will through this system get an opportunity for a triple win situation: contributing to national development, environmental protection and enhancing their own livelihoods. The big problem of relying on small scale farmers is organizing them to ensure service provisions that live up to the requirements of endurance, additionality and reliability. The Kenya Tea Development Agency [KTDA] for over almost 50 years has been successful in integrating 600,000 smallholders in tea production making tea number one income earner in Kenya, and enhancing the livelihoods of the involved contract growers. This article argues that lessons should be learned from the success of KTDA when trying to replicate the organizational model for other crops, but not least in PES schemes. The article emphasizes vertical integration and production diversification, enabling market conditions, and democratization as the main factors in KTDA's success. This could possibly be replicated when promoting small scale farmers participating in the post-Kyoto carbon trade and other PES schemes.
\end{abstract}

Keywords: Payment for environmental services, post-Kyoto carbon trade, agricultural development, Kenya Tea Development Agency, and smallholder contract farming.

\section{INTRODUCTION}

It is a well-established fact that agriculture plays a major role in reducing poverty and creating the foundation for economic growth in developing countries [1]. Poor developing countries, especially on the Africa continent, have a huge unused potential for agricultural production that must be utilized to feed a population that will keep growing rapidly for the next three to four decades, at least, and to overcome the widespread poverty already rampant. At the same time there is a growing recognition that agriculture is not so much a field-based enterprise as a landscape-based enterprise. Crops in individual fields are dependent on services provided by nearby ecosystems and nearby ecosystems are influenced by agricultural neighbors. Agricultural landscapes have the capacity to regulate environmental services, such as population dynamics of pollinators, pests, pathogens and wildlife, as well as levels of soil loss, water quality and supply, and greenhouse gas emissions and carbon sequestration ([2], p. 247). With dwindling natural resources and many ecosystems coming under a growing threat of not providing essential ecosystem services [ES], there is an increasing recognition of the need to decouple necessary economic growth - to cope with a growing population and eradication of poverty - from environmental impacts. This is especially pertinent for the accumulation of greenhouse gases in the atmosphere [3].

*Address correspondence to this author at the International Development Studies, Department of Society and Globalisation, Roskilde University, P.O. Box 260, DK-4000 Roskilde, Denmark; Tel: +45 4674 2908; Fax: +45 4674 3096; E-mail: mobh@ruc.dk
Reducing emissions from deforestation and degradation [REDD] together with carbon sequestration from agricultural landscapes is believed to come to play an increasing role in the international climate negotiations to replace the Kyoto Protocol after 2012. "For a sector that is often deemed a climate change problem, soil carbon has made the agricultural sector part of the climate change solution" ([4], p.19). Payment for environmental services [PES] or markets for environmental services [MES] have within mainstream economic thinking become new instrument in pursuing environmental protection at the same time as complementing traditional development assistance. In particular, the World Bank has been very active in raising funds to promote a carbon market and the financial flows through the carbon market are expected to surpass traditional development assistance in the post 2012 Kyoto Protocol era. In reporting from the preparatory meeting in Bonn leading up to the COP 17 in Durban, Shefali Sharma writes: "However, it is clear that the World Bank wants to ramp up its engagement in agriculture by convincing African governments in particular that agriculture could be a lucrative opportunity to attract carbon finance" [5].

However, the poorest developing countries and small scale farmers have so far benefitted very little from the Kyoto Protocol Clean Development Mechanism [CDM] as a significant portion of the emissions are concentrated in landuse activities, not all of which are currently eligible under the CDM. The result is that "The CDM currently only includes afforestation and reforestation activities and limits 
these LULUCF ${ }^{1}$ credits to 1 per cent of total CDM credits" [4]. The Least Developed Countries [LDC] only host $0.7 \%$ of all registered CDM projects and according to the World Bank, supported by a big number of developing countries, the CDM regulations should subsequently be reformed ([4], p.86).

The big problem that has puzzled economists and development scholars for long is how to organize small scale agricultural producers for whom the aim of cultivation is sustaining self-sufficiency livelihoods for the family with little consideration of higher societal goals of enhanced productivity, economic development and environmental protection. This article will discuss one outstanding example of an organization model, namely the Kenyan Tea Development Agency [KTDA] that has turned approximately 600,000 , previously subsistence small scale farmers into successful owners of a huge agribusiness company. This is the story of a good mix of diligent company management and enthusiastic smallholders who saw the economic benefits of planting tea for the relatively stable world market. But they also saw opportunities for democratic influence by joining KTDA and together with some luck and ability to manoeuvre in difficult political environments in Kenya for the past 50 years, KTDA has turned out to be an outstanding example of, in the beginning, a successful parastatal and since then an example of 'happy' [i.e. benefitting the small scale farmers] economic liberalization. It is an example of small subsistence farmers who have often been considered outside the reach of the market and societal development goals that, through a benign market transition, are buying shares and taking ownership of a huge agribusiness company.

The aim of discussing the KTDA success story is to learn about possibilities of replication of the organizational model in other cash crops, and in other socio-political and economic settings. It is not least to assess the possibilities of enhancing eco-friendly production systems through payment for environmental services. This could provide a winsituation for the farmers through enhanced livelihoods and a win-situation for the ecological environment through i.e. organic farming and maintenance of carbon stocks and carbon sequestering production systems and landscapes. The possibility of a win-win-win situation for farmers, the environment and national economic development justifies looking more closely at the organizational model. The approximately 2.5 billion small scale farmers in developing countries play a major role in good environmental stewardship and can through various models of payment for environmental services [PES] contribute significantly to decoupling the environmental impact from necessary increases in production to feed a growing population. The LULUCF CDM projects of the Kyoto Protocol have so far not attracted major investments due to the difficulties of ensuring reliability, additionality and endurance especially when implemented by smallholder farmers. The need to decouple a growing production - to care for a growing population and alleviation of poverty - from environmental impacts must necessarily involve the small scale farmers as the main environmental stewards in the global climate

${ }^{1}$ LULUCF stands for 'land use, land use change and forestry' that is one of three CDM mechanisms under the Kyoto Protocol. negotiations to replace the Kyoto Protocol. Poor, small scale farmers in developing countries and not least in South Sahara Africa should have a historic chance of benefitting from this. What is, however, important in discussing the possibilities for getting payment for environmental services through climate smart agriculture $[6,7]$ is the necessity for applying sustainable agricultural methods that will in any case benefit the farmers by improving their food security and agricultural practices [8].

The article is based on the authors fieldwork carried out among small scale KTDA out growers in Buret Division in Kericho District in Kenya in 1979 and a revisit to KTDA and farmers in the same area in $2011^{2}$. From interviews with farmers and KTDA officials and through studying the history of KTDA during the somehow tumultuous political times during the 32 years in between, the article will assesses under what conditions and to what extent a similar organizational model can be replicated and used as a vehicle for enhancing the livelihoods of small scale farmers and national economic development through projects that will also benefit the environment.

The following section 2 starts by discussing how PES could possibly come to play an important role in supplementing farmers' incomes at the same time as enhancing agricultural management for increased food security. Looking at the successor of the Kyoto Protocol and its Clean Development Mechanism in particular and how an organizational model for organizing environmental services providers could play a crucial role in the success of this by easing the inherent problems of monitoring [measuring], reporting and verification [MRV] through an integrated and democratic agribusiness model. The ensuing section 3 of the article will describe the elements of the success of KTDA as an organizational model for integrating smallholders in the Kenyan tea production and will summarize in section 4 how this model could possibly be replicated in organizing environmental service providers, also for a future carbon market.

\section{HOW COULD PES BE USED FOR DECOUPLING INCREASED PRODUCTION FROM ENVIRON- MENTAL IMPACTS?}

According to a much used definition PES means: "[a] a voluntary transaction where [b] a well-defined environmental service [ES] or land use likely to secure that service [c] is being 'bought' by a [minimum one] service buyer [d] from a [minimum one] service provider [e] if and only if the service provider secures service provision [conditionality] ([9], $\mathrm{p}$. 835). A special issue of the journal Ecological Economics

\footnotetext{
${ }^{2}$ The 1978-79 study consisted of a $10 \%$ random sample of the first 2000 outgrowers attached to KTDA in Buret Division in Western Kenya. Data were collected on the total farm size, acreage of tea, delivery of green leaves and incomes from the tea production for the 200 individual outgrowers. Out of the 200 surveyed farmers a stratified sample of 24 farmers [divided into 'rich', 'middle' and 'poor' farmers, based on the income from tea production] was selected for in-depth interviews according to a farming system approach, see i.e.: [24]. The follow-up study was carried out in January 2011. Apart from thorough discussions with the KTDA Management at HQ level, in-depth interviews were carried out with factory management and a selected number of 'rich', 'middle' and 'poor' farmers in the Buret Area in Kericho District, focussing on how they saw the role of KTDA as an organizational model for income generation, food security, enhancement of livelihoods and democratization.
} 
[Vol. 65, 2008] documented the experiences gained from implementing PES that started mainly as user-financed programmes, the inspiration came from Vittel's drinking water protection programme in France which is a wellknown example for its simplicity and well-functioning. In that case 27 dairy farmers are paid by the water producer Vittel to use best practices in dairy farming including avoiding agro-chemicals in the limited catchment of 5100 ha. [9]. This example of a small, well-defined environmental service from a well-defined number of ES providers and a well-defined buyer has now been complemented with a large number of government-financed programmes supported by a large number of bi- and multilateral donors. The findings from the cases presented in the 2008 special issue of Ecological Economics pointed to the user-financed PES programmes as being much more likely to be more efficient than government-financed ones that were found to be hijacked for many alternative purposes ([9], p. 851).

Under the present Kyoto Protocol climate regime the, CDM has been used to safeguard the greenhouse gasses [GHG] emissions of the developed countries at their present high level, due to the possibility of investing in CDM projects in developing countries. Of the three types of CDM projects, the two promoting clean technologies to reduce emissions of GHGs have attracted by far the majority of investments while the only sink type of project, the LULUCF projects, has proven very difficult to implement and has subsequently attracted less interest with only one CDM forestry project registered up to May 2008 ([10], p.744). In particular, the World Bank is, through its BioCarbon Fund, pushing for "sectors such as forests and agriculture, to expand the benefits of the Clean Development Mechanism" ([4], p. 5) and in general to have more LULUCF projects to be validated as CDM projects and enter the Kyoto market ([11], p. 1958). According to World Bank Carbon Finance, $70 \%$ of the climate mitigation potential in agriculture is found in developing countries ([4], p. 19). Since land use contributes $20-30 \%$ of global emissions, there have in the on-going international negotiations leading up to a successor of the Kyoto Protocol, been many efforts to incorporate the carbon accounts from land use changes, agriculture and forestry in a carbon market. This could compensate the environmental stewards in the developing countries the opportunity costs of maintaining the carbon stocks and sequestering capacities of different land uses, especially tropical forests. These efforts have changed names from RED [on deforestation] to REDD [deforestation and degradation] to REDD+ [definition of forest] and the latest version, REDD++ that also includes agriculture. To avoid many of the definition problems concerning what a forest is, and how to measure deforestation and degradation, CIFOR in Indonesia is now proposing a new concept: REALU, signifying Reducing Emission from All Land Uses [12]. This approach proposes a holistic landscape approach, including agricultural activities and as such the need to effectively organize the many small scale farmers in these landscapes.

Following the Kyoto Protocol, an important factor in considering a CDM project for funding is whether it will contribute to sustainable development in the host country. Although the concept of sustainability is poorly defined, there are many reasons why LULUCF projects would have a better chance of fulfilling this requirement than other CDM projects as these types of projects could be implemented by local communities [many of whom are among the poorest groups in the world] who by default are the main environmental stewards in the developing countries. The main problem in promoting LULUCF projects has been to ensure reliability, endurance or permanence and additionality [and avoiding leakage], especially if smallholders are involved in the implementation. This concern also goes for the so-called perverse incentives, such as offering payment for reforestation that could induce deforestation in order to subsequently attract payment ([9], p. 847).

The technical and administrative complexities involved in the CDM process for LULUCF projects have for a long time been a major concern for many developing countries wishing for the UNFCCC process to be of help for them to conserve existing forest areas and the restoration of degraded land for eco-friendly productions. Mexico sees this as reflecting the international community's mistrust of civil organizations and rural communities in the developing world ([11], p. 1964). According to Corbera and Brown there exist three main types of institutional schemes through which carbon forestry offsets are commercialized in developed and developing countries ([11], p. 1958). In addition to the CDM process that hardly allows sink projects like LULUCF, there are the non-Kyoto voluntary markets that have, however, not been very efficient in generating a viable market for environmental services. The third type is state-based schemes for the commercialization of carbon which aim to establish an enabling policy framework which will progressively involve national civil society and investors in trading ecosystem services. It is, therefore, not a real market as the price of carbon offsets is dependent on the state-based and other investors' willingness to pay and the emission reductions cannot be traded in the Kyoto market. Latin American countries like Costa Rica, Mexico, Ecuador and Brazil have put in place institutional structures for ecosystem management with prices oscillating between USD 4 and USD 9 per tons of CO2 equivalent ([11] p. 1961).

Based on the review of a number of PES programmes, Arild Vatn draws the conclusion: "that PES is not first of all about moving from public policies to market allocations. It is more about a reconfiguration of state-market-community relationships. Hence, PES is rather about another way of using the capacities and funds of states and communities than about abandoning them. As far as there is a clear market component involved, the material reviewed has shown that establishing markets is moreover a demanding process of social and political construction" ([13], p. 1251). One major reason for the difficulties in establishing a market is the very high transaction costs involved in establishing and monitoring a LULUCF project. With an agreement on manageable ways to measure and monitor carbon stocks in different types of vegetation and agricultural landscapes through a combination of satellite surveillance and ground truth, the next challenge is the organization of the service providers. One way of reducing the transaction costs of organizing smallholders is through using the power of representative bodies - i.e. hierarchies - or by increasing the necessary trust and engagement - i.e. communities [13]. As I shall show in the following, KTDA has established both the institutional hierarchy of representative bodies and the 
necessary trust and engagement among its growers - a model that could possibly be replicated.

\section{THE ACHIEVEMENTS OF KTDA}

Over the years there has been a lively debate on the role of agribusiness and contract farming, especially in a developing country context. The literature gives ample examples of how agribusiness has made small-scale farmers dependent on mono-cropping, often at the expense of selfsufficiency and food security from a dependency theory point of view [see i.e. [14, 15]]. Much literature has also pointed to the diversification of agribusiness and its diverse role in development [see i.e. [16, 17]]. In this context, I find KTDA an encouraging example of promoting enhanced livelihoods and democratic participation among the attached out growers as the same time as they have contributed to national economic development in Kenya.

Tea has become the biggest export commodity in Kenya, earning a record of 97 billion Kenya Shillings [approximately 8 billion USD] in 2010 and as such overtaking both horticultural products and tourism that became second and third biggest foreign exchange earners respectively [Daily Nation 25.1.2011]. Kenya is now the second largest exporter of black tea in the world and KTDA is one of the largest tea management and trading companies in the world [KTDA Annual Reports]. KTDA and the small scale tea growers have a major share in this success. It is as such remarkable that KTDA's organization model has drawn so little attention from the international researchers' community, only a very few references can be found in the literature.

Tea was introduced in Kenya in 1903 and the colonial settlers started growing tea on a commercial scale in Kenya in the 1920s but it was not before the Swynnerton Plan of 1954 that African farmers were allowed to grow cash crops. The purpose of the Swynnerton Plan was to defuse the African unrest and resistance towards the British colonial rule by creating an African middle class of farmers who got private title deeds. The Swynnerton Plan started the adjudication of land with a view to enhance cash crop production and individual economic performance among the subsistence small scale farmers [18]. The Swynnerton Plan was a somehow successful land reform program that rapidly increased small scale farmers' production of, especially, coffee and tea. The coffee farmers were mainly organized in cooperative unions that showed varying degrees of performance in assisting the farmers with production input, credits and marketing. The small scale tea farmers were from the beginning organized by the Special Crops Development Authority [SCDA] that after independence was replaced by the Kenya Tea Development Authority [KTDA], which was established as a parastatal in January 1964. After the establishment of KTDA, the number of small scale farmers grew rapidly and the acreage cultivated and amount of tea produced by the small scale farmers soon became a major competitor to the multinational large scale estates as shown in Table 1.

The number of KTDA owned tea factories and buying centres has followed the increase in the production of green leaves by the growers. In 2011 there were 54 KTDA factory companies owned by 150,000 tea farmer shareholders running a total of 65 tea processing factories. KTDA has managed to establish a world known brand and KTDA teas obtain approximately half a US dollar above average per $\mathrm{kg}$ at the tea auctions. The multinational tea companies now buy KTDA teas to blend with their own estate teas to obtain a better grade [21]

\subsection{Inclusiveness of KTDA Farmers and Social Development}

The present requirement to become a KTDA grower is the planting of a minimum of 875 tea bushes that given an average of 3500 stumps per acre requires a minimum of 0.4 acres or about 1600 sq. meters. Table 1 shows a national average of 0.2 ha or 2000 sq. meters per grower in 2010 . This is only about half of the average tea plot in 1978 when the author conducted field work in Kericho district. The slightly bigger farm sizes in Kericho district allowed for a bigger average of 0.55 ha, although the median of the random sample of 200 growers was only 0.45 ha. This resulted in a marked socio-economic differentiation singling out a group of well-to-do farmers mainly using wage laborers for producing tea and poorer farmers relying entirely on family labor for the tea production and supplementing the cash income by working as casual laborers for the well to do farmers. The main findings from the 1979 study, however, was that the tea production greatly enhanced the livelihoods of all involved tea growers who invested the economic surplus from the production in enhancing other cash crop production, such as hybrid maize and graded cows for milk production as well as for education of their children [22].

During the initial phase of establishing KTDA, the farmers were required to have a minimum of at least two acres to participate in the programme as it was essential that the farmers also had land for their subsistence production. This of course left some farmers out, especially in the high density areas like Kisii. Now these requirements have been abolished and a minimum of 875 stumps $\left[\begin{array}{lll}1 / 4 & \text { acre }]\end{array}\right.$ introduced to make it economically viable to include farmers in the KTDA scheme. In Kisii this minimum requirement is set as low as 500 stumps, considering the small average size of land holding in that district [21].

Table 1. Performance of KTDA Small Scale Tea Farmers

\begin{tabular}{|c|c|c|c|c|c|}
\hline Production Year and Reference & $1964(2)$ & $1978(4)$ & $1994 / 95(1)$ & $2002(2)$ & $2010(3)$ \\
\hline Number of KTDA Growers & 19.000 & 122.300 & 289.270 & 360.000 & 560.000 \\
\hline Hectares Cultivated & 4.700 & 46.900 & 68.400 & 85.000 & 112.000 \\
\hline Percentage of Total Kenyan Tea Production & 2 & 34 & 67 & 60 & 62 \\
\hline
\end{tabular}

(1) [19], (2) [20], (3) [21], (4) [22]. 
The discussions during the years of the minimum land required to become a KTDA grower also reflect the enduring contestation between the three main stakeholders in the development of the KTDA, namely the Kenyan state, the foreign stakeholders ${ }^{3}$ and the smallholder out growers. An extremely important explanation for the success of KTDA is exactly the 'balance' resulting from the contestation among the main stakeholders that according to Ochieng resulted in firstly a vertical integration of the production chain from provision of input [fertilizers, extension services, credits etc.] to collection of green leaves, manufacturing of made up teas and finally marketing of the KTDA teas. Secondly, democratization through inclusion of smallholder representatives on the KTDA board of directors [1960s], followed by introduction of grower shareholding [1960s through the 1990s] and finally privatization with the farmers gaining ownership of the entire organization [2000], these steps of gradual democratisation were all an integrated part of the success [20].

One quarter of the small scale tea growers, 150,000 out of approximately 600,000 growers, have bought shares in KTDA and can elect and are elected as directors of their tea company and possibly, through one of the 12 tea zones, elect or be elected as directors of the KTDA Management Company. This potential bias between well off shareholders and the three quarter of the growers being only producers, together with the minimum land requirement for participation in the programme, could potentially create an uneven economic development and social differentiation among the smallholders that could lead to poorer farmers selling their land to richer farmers or the appearance of social tensions being detrimental to further rural economic development. While the 1979 study showed a socioeconomic differentiation among the small scale KTDA out grower farmers, mainly based in their interests in growing tea living up to the minimum quality standards, such as plucking only two leaves and the bud, the study showed no signs of poorer farmers selling their land to richer farmers. Less well-off farmers were more dependent on family labor and working as casual laborers for the richer farmers, many of whom are entirely dependent on wage labor for growing tea [23].

The 1979 field study is entirely in line with Ochieng when he suggests that:

“...contract farming can play a positive or negative role in rural development, depending - at least in part - on the socio-economic and political relationships and structures under which it is embedded... and confirms that, contrary to conventional opinion, smallholder farmers may be poor but that does not necessarily mean that they are not efficient, entrepreneurial, brand- or value-conscious" ([20], p. 154).

The contract farmers growing tea for KTDA were in a much better position than the contract farmers producing

\footnotetext{
${ }^{3}$ The Commonwealth Development Corporation [CDC] and the World Bank originally provided the capital for the KTDA tea factories that were in the initial years managed by multinational tea corporations, like Brooke Bond and James Finlay, who own the competing large scale tea estates.
}

sugar. The findings from the 1979 study suggest that the balance between cash crops and self-sufficiency food crops was much better in the tea areas than in sugar production areas where the popular saying: 'sugar eats all' describes the cash crop dependency and neglect of food crops among the smallholder sugar farmers. Ochieng rightly points to, in addition to this rigidity, the differences in political patronage between the two crops during the presidency of both Kenyatta and Moi whose constituencies both hailed from the tea producing regions while the opposition had its constituency among the sugar producers in Western Kenya [20].

\subsection{Is Replication of the KTDA Model Possible?}

The KTDA model has greatly enhanced the livelihoods of approximately 600,000 smallholder tea growers and the approximately 3 million people are directly or indirectly dependent on the KTDA industry. Further it has had a major role in making black tea Kenya's prime export earner and as such creating national economic development. These two facts are convincing justification for investigating the preconditions for its possible replication in other cash crops or ES and in other socio-political settings in the developing countries.

With an increasing pressure on environmental resources and concerns of deteriorating ecosystems due to pollution of soil, air and water besides the increasing concentration of greenhouse gasses in the atmosphere, there will most likely be a growing demand for involving the huge numbers of small scale farmers in the developing countries, as they are the main environmental stewards. In the struggle for improved environments to sustain a growing population, means must be found to pay the farmers for providing environmental services. Both organic farming and vegetal coverage of landscapes and soil management for carbon sequestration can, together with other environmental services, play important roles in the endeavour to decouple an increased production from environmental impacts [3]. The aim is to find the formula for the triple win-win-win situation of environmental protection, enhanced livelihoods for small scale farmers and national economic development. The organization of small scale farmers is a necessary prerequisite for this endeavour.

Based on the 1979 Study, the revisit in 2011 and studying the development in the intervening more than 30 years, my findings strongly suggest three broad areas for further investigation, in analyzing the preconditions for the possible replication of the KTDA model. These three areas seem to have played a pertinent role in the success of KTDA and their preconditions should be studied in order to know if they are replicable in other socio-political, development contexts.

\subsubsection{Vertical Integration and Diversification}

The delicate balance between vertical integration in producing a specific crop and diversification seems to be of crucial importance to enhance the efficiency of the smallholder production without creating dependency that will erode the long term sustainability. The provision of input, such as high quality vegetative propagations [VP] from KTDA's own tea plants and the dissemination of technical knowhow for the farmers now producing their own 
VPs and adopting the 'two leaves and the bud' plucking policy resulting in harvesting high quality teas, has been an important part of the package. This has been made possible through KTDAs own extension service that was made efficient by providing the extension officers with means of transport and other facilities enhancing the motivation of their work. The Kenya Tea Research Foundation through many years of research in determining the optimal conditions for enhanced production has given specific direction for use of chemical fertilizers that is supplied by KTDA at slightly subsidized prices. Recommendations on planting density, pruning and not least the optimal plucking of two leaves and the bud, have been disseminated to the small scale farmers through regular barassas [open air meetings] and the extension service. To make the delivery of green tea to KTDA attractive [apart from the legal obligation] farmers receive a regular monthly payment according to the quantity of green leaves delivered and an annual bonus according to the quality of the processed tea from the factory they are delivering to and the price it obtains at the auctions in Mombasa or London.

There have, over the years, been many complaints from the producers about low prices of green leaves. The farmers' representatives in the boards of their own factory companies and at the KTDA Headquarters have helped in making the price structure transparent and the farmers to understand that given an average world market price of made up tea it is the quantity and quality of the green leaves they deliver that determine the economic outcome of their efforts.

The dangers of a contract farming system as KTDA are listed by Ochieng under five headings:

- $\quad$ Shifting market and production risks to smallholders through low prices

- $\quad$ Shifting burden of quality and quantity standards to smallholders through using their labor power both more intensively [longer hours] and extensively [unpaid family labor]

- $\quad$ Restricting smallholders' rights to alternative use of their land and thereby reducing them to wage laborers

- Encouraging mono-cropping and other production practices which lead to environmental degradation

- Increasing socio-economic differentiation among the peasantry by excluding small and poor farmers or by disintegrating the peasantry through the creation of a peasant capitalist class [20], p. 138].

There is no doubt that the KTDA contract farming system has increased the socio-economic differentiation among the farmers in the tea areas as it was also shown in the 1979 study [22]. The study also showed that KTDA at that time encouraged tea farmers not to grow more tea than they could also ensure their susistence food production. Furthermore the economic surplus from the tea production was to a large extent invested in other cash crop commodities, such as milk with graded cows and increased corn production based on hybrid maize species.

The socio-economic development among the KTDA smallholders seems best described as a benign capitalist development process where vertical integration has enhanced the productivity, both in quantitative as well as in qualitative terms, and created a socio-economic development and differentiation among the smallholders without excluding major parts of the peasantry. The diversification of production originally promoted by KTDA has prevented turning the smallholders into wage laborers for KTDA, but the farmers have, on the contrary, to a large extent retained their status as independent farmers - some better off, hiring other farmers as laborers who, most of them, work as casual laborers to earn an income to supplement their own farm production. These poorer farmers rely more on family labor, including the children in their tea production, but the tea production also gives them better opportunities for improved farm management and diversification as well as educating their children.

\subsubsection{Enabling Market Conditions}

There is no doubt that the relatively stable world market prices and the slowly but constant growing demand for tea has been an important contributor to the success of KTDA. That success is, however, also very much due to KTDA maintaining high quality teas that fetch approximately 50 US cents higher prices per $\mathrm{kg}$ than average auction prices. No producers of primary products can safeguard themselves from fluctuating world market prices. This has been one of the main obstacles to economic development in developing countries producing primary commodities. It is, therefore, important to command as big a share of the entire value chain from soil to table of the commodity in question. KTDA has been successful in gradually taking over the management of the tea factories, although the foreign stakeholders [the multinational tea companies who originally had management contracts with the KTDA tea factories, supported by the CDC and the World Bank] claimed that the manufacturing, marketing and retailing functions were technically demanding and that rushed Africanization could jeopardize the future of the entire smallholder project [20], p.149]. It was only by the then very dynamic General Manager of KTDA, Charles Karanja, who came from the same constituency as President Kenyatta who took the matter directly to the President and got his support for KTDA taking over the management of the tea factories [20]. Chai Trading Company Ltd. is a subsidiary of KTDA and sells the tea at Mombasa auctions and receives 25\% of direct sales. Kenya Tea Packers pack the tea for the domestic market that, however, only consumes about $4 \%$ of the Kenyan tea production. The bulk of the made-up tea is sold at the auctions to major trading companies who take a significant share of the value in the chain based on the retailing prices KTDA teas obtain at the overseas markets. Approximately $75 \%$ of the KTDA tea is sold at the auctions and so far there have been no direct sales to supermarkets and chain stores, which could be a new frontier for KTDA [21].

As the case with KTDA taking over the management of their tea factories shows, it is technical competencies combined with political power that determine the share of the value chain to be commanded by the various stakeholders in the production chain from soil to table. The heart of the development problem is the lack of both in most developing countries which well managed agribusiness and contract farming systems could help making up for. An increasing need for environmental services, not least the 
reduction of GHG in the atmosphere, will enhance the market position for the providers of these environmental services.

\subsubsection{Democratization and Political Support}

Interviewing different types of KTDA farmers, both the well to do and the poorer farmers as well as those in between confirmed both in 1979 but even stronger in 2011 that their active and democratic participation in KTDA was a major contributor to their enthusiasm in producing tea and being a KTDA farmer. As most farmers worldwide will do, the tea farmers keep comparing the market prices of alternative crops and self-sufficiency production for the family to assess the economic benefits of growing tea. With fluctuating prices on most primary products some crops might appear more economically beneficial for shorter periods of time, as sugar did during my visit and interviews with the farmers in January 2011. But even with temporarily higher prices on alternative commodities, such as sugar at that time, the social-political factors of being a KTDA farmer with democratic influence in their own companies played a major role for their decisions to keep cultivating - and even expanding - their tea plots.

The 1979 study showed a marked difference in the smallholder tea growers in Kericho District and the smallholder sugar farmers both in Nyanza and Western Provinces. The tea farmers only planted smaller parts of their plots with tea, leaving the rest for cash crop diversification and for improved self-sufficiency with food crops. The income from the tea production was in general productively invested while the incomes from the sugar production were, to a much larger extent, used for consumption with little regard for crop diversification and self-sufficiency. Price fluctuations for the sugar also were greater than for tea. The income per ha of tea was higher than for sugar, tempting the sugar farmers to plant most of their land with sugarcane. It is hard to say to what extent these two factors of price fluctuation and farm management explain the differences in the success of the respective smallholder schemes, or to what extent it is due to the political patronage - as claimed by Ochieng - of first president Kenyatta and since Moi whose constituencies hailed from tea growing areas while the opposition hailed from the sugar areas in Nyanza and Western provinces.

My findings from studying the KTDA confirm Ochieng's balanced assessment of the role of the various stakeholders in the success of the contract farming system:

"It was this coincidental congruence of interests or the prevailing socio-economic and political structures and relationships between the state, agribusiness and smallholders that ensured the evolution of a fairly democratic and broad-based smallholder ownership and control of the KTDA while maintaining its high technical and managerial expertise"....'It also demonstrates that neither the state, agribusiness nor smallholders are “homogenous"” ([20], p. 154).

The various studies of the KTDA contract farming model largely confirm that the vertical integration of the smallholders together with the gradual democratization and integration of the smallholders in the policy formulation and management of the KTDA that resulted in the 'happy liberalization' of KTDA in 2000, is the main explanation of KTDA's success. Obviously the world market for tea with rather stable prices has been an important factor adding to the success as well as it is obvious that contract farming models like KTDA will only succeed with some political backing or at least with no strong political opposition to its success. However, it is important to keep in mind that the empowerment of a big number of small scale farmers in itself is an important political achievement that forms the basis for further economic and socio-political achievements.

\section{ORGANIZING SMALL SCALE FARMERS IN PAYMENT FOR ENVIRONMENTAL SERVICES SCHEMES}

The development of the KTDA organizational model is obviously historically and politically contextual. Nevertheless, it is believed that a number of lessons could be learned from the model for its replication for other crops and environmental services, taking into account vertical integration and diversification, the enabling market conditions and the democratization and political support, as described above.

If the model is to be replicated in relation to PES programmes, the ES must be clearly defined as well as its market with clearly defined ES providers and ES buyers. Even if the PES programme will not function as a free open market [as was the intention with the Kyoto Protocol CDM] but rather be supported by state-based buyers using tax payers money, the PES approach will be useful in more clearly defining the ES, its providers and its buyers and hence the price of the ES. It is important to keep in mind that most environmental services are considered public goods that used to be there in plenty for free. As it has been gradually realized, and will be realized with greater speed in the future, that these services can no longer be taken for granted, the market definitely can serve in identifying the providers and buyers of ES and establishing the right price level. This is a process that will take time and it is suggested that the tasks should be divided into three separate avenues of investigations that should collaborate closely:

Technical and natural science identification and delimitation of the environmental service in question [e.g. environments for producing an organic product, maintenance of watershed for downstream water availability, soil management and maintenance of agricultural landscapes for carbon sequestration and storage, etc.] and their environmental implications

$\rightarrow \quad$ Social science identification and delimitation of groups of smallholders and analysis of preconditions for vertical integration of smallholders in contract farming schemes that will provide the attraction of democratic participation and necessary political support to ensure the reliability of ES providers. The reliability of the ES providers must be verified by effective and manageable monitoring, reporting and verification [MRV] tools at landscape levels by combining satellite images and measures of ground truth. An efficient organizational model for MRV, like the KTDA model, is essential in this connection. 
$\rightarrow \quad$ Identification of private buyers of ES or more realistically private/public partnerships or pure public funding seeking to decouple increasing production from environmental impacts. Identification of the ES, its providers and buyers must result in a price that is viable for the ES providers. In the case of the carbon market in the existing Kyoto Protocol regime, this requires that the complexities of present $\mathrm{CDM}$ procedures will be changed and procedures for establishing additionality and monitoring endurance/permanence and reliability be simplified to allow small-scale farmers to economically benefit as ES providers.

The many on-going international negotiations to find a successor to the Kyoto Protocol and the widespread acknowledgment of the need to simplify the procedures for including LULUCF or REALU projects for more developing countries to participate in mitigating the concentration of $\mathrm{GHG}$, leave some room for optimism. As mentioned above, the World Bank's Carbon Finance Facility has been instrumental in promoting agriculture and land management programmes to benefit from the carbon markets and the Kenya Sustainable Agricultural Land Management Project is the first project in Africa that sells soil carbon credits, improving the livelihood of rural communities while at the same time addressing both climate change mitigation and adaptation ([4], p. 19). Lessons should be learned from these innovative experiments with a view of analyzing if a KTDA model of organizing small scale farmers could possibly enhance the efficiency in organizing the providers of the environmental services. It is believed that this could form the basis for developing a realistic and manageable MRV system to reduce the transaction costs of including the land use projects in a new carbon market.

\section{CONCLUSIONS}

Considering the rather tumultuous periods Kenya has been through throughout its existence as an independent state, and the poor performance of African small scale agriculture in general as well as the lack of economic and democratic development in most African countries, the KTDA experience is an outstanding example of success. As the population of Africa according to various estimates is going to increase to about two billion by the middle of this Century. Considering the already widespread poverty, Africa must utilize its rich agricultural resources to cope with this challenge. Africa will provide the lion's share of the increase in the global population, which is expected to reach between nine and eleven billion by 2050 . This will challenge Africa's and the wider world's resources and assimilation capacity and thereby the global climate negotiations with an unavoidable demand to decouple the necessary economic growth - to cope with the increasing population - from environmental impacts.

The small scale farmers are the biggest group of environmental stewards who could benefit in various ways from payment by environmental services. With the on-going negotiations for a successor to the Kyoto Protocol and the prospects for including a carbon market where the ES is certified emission reduction units through maintenance of agricultural production systems and landscapes. This requires manageable MRV systems where reliability, endurance and additionality are ensured. The precondition for that is an institutional organization of smallholders that will provide them with the necessary tools and knowledge to allow them to participate efficiently in the scheme but will also provide a democratic framework that allows for farmers' active participation and say in policies framing their livelihoods. In this way agricultural land management and maintenance of agricultural landscapes for environmental services can assist in enhancing the livelihoods of small scale farmers and national development in Africa and other developing countries at the same time as playing a pertinent role in decoupling a necessary increase in production from its environmental impacts.

KTDA has shown to be an outstanding example of such an organization and the challenge is to see how this model can be replicated for other crops and payment for environmental services in other socio-economic and political settings. A future carbon trade seems especially promising for this.

\section{ACKNOWLEDGEMENT}

I owe many thanks to the farmers in Buret Division in Kenya sharing with me their aspirations, hopes and problems as smallholders and many thanks to the KTDA management and staff for giving me time to learn about the KTDA organisation. Also many thanks to my colleagues for good advice on earlier drafts of this article and thanks to the SLUSE programme for providing funds for the follow-up study in 2010.

\section{CONFLICT OF INTEREST}

The author confirms that this article content has no conflicts of interest.

\section{REFERENCES}

[1] World Bank. World development report. Agriculture for development 2008.

[2] Swinton SMea. Ecosystem services and agriculture: cultivating agricultural ecosystems for diverse benefits. Ecol Econ 2007; 64(2): 245-52.

[3] UNEP. Fischer K, Swiling M, von Weizsaleker EU, et al. Decoupling Natural Resource Use and Environmental Impacts from Economic Growth. A report of the working group on decoupling to the International Resource Panel. 2011; pp. 1-174.

[4] Carbon Finance at the World Bank. Carbon finance for sustainable development 2010; p. 10.

[5] Sharma S. Agriculture to feature as a key issue on the road to Durban: opens up critical debates. Institute for Agriculture and Trade Policy, June 27, 2011.

[6] World Bank. Opportunities and challenges for climate-smart agriculture in Africa 2011; Available from: http://climatechange. worldbank.org/sites/default/files/documents/CSA_Policy_Brief_we b.pdf [cited: $24^{\text {th }}$ May 2012].

[7] Negra C, Wollenberg E. Lessons from REDD+ for Agriculture. 2011;CCAFS Report No. 4.

[8] Large TL, Torrico JC. LULUCF projects under the CDM: an opportunity to increase food security in developing countries. Cienci Agro 2009; 1(4):152-9.

[9] Wunder S, Engel S, Pagiola S. Taking stock: a comparative analysis of payments for environmental services programs in developed and developing countries. Ecol Econ 2008; 65(4): 83452.

[10] Corbera E, Soberanis CG, Brown K. Institutional dimensions of payments for ecosystem services: an analysis of Mexico's carbon forestry programme. Ecol Econ 2009; 68(3): 743-61. 
[11] Corbera E, Brown K. Building institutions to trade ecosystem services: marketing forest carbon in Mexico. World Dev 2008; 36(10): 1956-79.

[12] van Noordwijk M, Minang P, Dewi S, Hall J, Rantala S. Reducing Emissions from All Land Uses [REALU]: the case for a whole landscape approach. ASB Policy Brief 13, ASB Partnership for the Tropical Forest Margins, Nairobi, Kenya 2009.

[13] Vatn A. An institutional analysis of payments for environmental services. Ecol Econ 2010; 69(6): 1245-52.

[14] Dinham B, Hines C. Agribusiness in Africa. A study of the impact of big business on Africa's food and agricultureal production. London: Africa World Press 1984.

[15] Feder E. Strawberry imperialism. An inquiry into the mechanisms of dependency in Mexican agriculture. The Hague: Institute of Social Studies 1977.

[16] Glover D, Kusterer K. Small farmers, big business: contract farming and rural development. London: Macmillan Press Ltd. 1990.

[17] Kirsten J, Sartorius K. Linking agribusiness and small-scale farmers in developing countries: Is there a new role for contract farming? Dev SA 2002; 19(2): 503-29.
[18] Heyer J, Maitha JK, Senga WM. Agricultural development in Kenya: an economic assessment. Nairobi; London: Oxford University Press 1976.

[19] Ongile GA. Gender and agricultural supply responses to structural adjustment programmes. A case study of smallholder tea producers in Kericho, Kenya 1999; Research Report No. 109.

[20] Ochieng, Cosmas, Milton, Obote. The political economy of contract farming in tea in Kenya. The comparative political economy of development. Africa and South Asia: Routledge 2010; pp. 136-57.

[21] Buch-Hansen M. Personal communication with KTDA Management in January 2011.

[22] Buch-Hansen M. Agro-industrial production and socio-economic development. A case study of KTDA smallholder tea production in Buret, Western Kenya 1980; p. 11.

[23] Buch-Hansen M, Marcussen HS. Contract farming and the peasantry: cases from Western Kenya. Rev African Polit Econ 1982; 9(23): 9-36.

[24] Norman DW, Worman FD, Siebert JD, Modiakgotla E. The farming system approach to development and appropriate technology generation. Rome: FAO 1995.

(C) Mogens Buch-Hansen; Licensee Bentham Open.

This is an open access article licensed under the terms of the Creative Commons Attribution Non-Commercial License (http://creativecommons.org/licenses/by$\mathrm{nc} / 3.0 /$ ) which permits unrestricted, non-commercial use, distribution and reproduction in any medium, provided the work is properly cited. 